\title{
The Research of the Preference of Public Instrument in City M's National Sanitation City Construction
}

\section{-Analyzed with China Mobilized Governance}

\author{
Yan Liu \\ School of Public Administration, Jinan University, Guangzhou, China \\ Email: 13560414740@163.com
}

How to cite this paper: Liu, Y. (2018) The Research of the Preference of Public Instrument in City M's National Sanitation City Construction-Analyzed with China Mobilized Governance. Open Journal of Social Sciences, 6, 95-105.

https://doi.org/10.4236/jss.2018.68007

Received: July 20, 2018

Accepted: August 13, 2018

Published: August 16, 2018

Copyright $\odot 2018$ by author and Scientific Research Publishing Inc. This work is licensed under the Creative Commons Attribution International License (CC BY 4.0).

http://creativecommons.org/licenses/by/4.0/

\begin{abstract}
As a kind of policy tools with strong Chinese characteristics, Mobilized Governance has a deep historical origin. Moreover, it has become the preference of public governors when they faced with internal public issues. This paper based on the case analysis of $\mathrm{M}$ city, in which taking a series of policy measures of "Mobilized Governance" in the process of constructing the National Sanitation City (Chuang Wei) to achieve policy objectives, and explores the intrinsic logic why "Mobilized Governance" has become the policy tool selection preference of public governors. And the final conclusion is that the path dependence of political mobilization, the limitation of policy resources, and the structural limitation of bureaucratic system are the reasons for this preference.
\end{abstract}

\section{Keywords}

Mobilized Governance, Policy Tool, National Sanitation City Construction

\section{Introduction}

For a long time, Chinese government seems to prefer the policy tools and governance logic of Mobilized Governance to achieve their governance goals in dealing with social public problems. This particular policy tendency reflects to a certain extent that in the current rapid social transformation in China, the policy tools that the government can choose and use are not infinite. Mobilized Governance is a kind of ways that the governance body taking advantage of their own resources and breaking the routine procedures to solve the vital or serious 
social problems. With the characteristics of discontinuity, temporariness and coerciveness, Mobilized Governance is also criticized for resource wasting and series of hazardous influence. But why Mobilized Governance is still the preference of public managers in some areas of governance? This article takes a series of "campaign-style" moves launched by M City to promote the "Construction of National Sanitation City" policy as an example to deeply analyze the internal logic of the government's choice of Mobilized Governance and explore why the government prefers Mobilized Governance among many policy tools?

\section{Mobilized Governance: The Choice Preference of Chinese Government Governance}

\subsection{The Connotation Characteristic of Mobilized Management}

As far as the word "mobilized" of mobilized governance is concerned, it is actually a process of dynamic movement. Toits connotation, scholar Feng Zhifeng made a detailed definition [1]: mobilized governance refers to the political subject who possessing specific political power, using the political power and administrative functions to maintain the social stability and due order. Through the political mobilization, from top to bottom, the public managers arouse the enthusiasm and creativity of their own class and other members of society to implement a kind of special treatment, which is well-organized, purposeful, and participated with large-scale people to solve the certain sudden events or major domestic long-delayed social problems. As a matter of fact, it is a governance tool for the public managers to achieve a certain goal. It has distinctive features such as temporary, results-oriented and mandatory.

\subsection{The Chinese Government's Preference for the Mobilized Governance}

At present, the Chinese government, especially the local government, has consistently showed a preference during the governance process, that is, they prefer to solve the urgent and easy-to-effective problems currently faced. The Mobilized Governance has a clear results-oriented approach and high degree of legitimacy inheritance from top to bottom. Therefore, Mobilized Governance is the preferred policy tool for local governments and even the state to initiate extensive mobilization and implement policy decisions. This choice has its own historical and realistic nature. On the one hand, although the current mobilized governance is different from the political movement before the period of Reform and Opening-up, the starting point of any new stage is the accumulation of the past experience, political behaviors and concepts. The current mobilized governance model is highly correlated with the government's governance model since the founding of the PRC. To a certain extent, China is still a country where institutional norms are subject to non-institutional factors. During the process of goal setting and policy tools selecting and executing, the governors are often in the hope of that a storm-like movement will achieve the set goals, so there is a 
path dependence when choosing Mobilized Governance [2]. On the other hand, when the government's governance achieves its stated goals, it is vulnerable to the scarcity of policy resources and the division of specialization and strict functional boundaries brought about by the bureaucratic structure. Therefore, in order to achieve effective governance in the short term, the governments have to break through the original institutional constraints and give away to the Mobilized Governance that can effectively concentrate social resources within a short time to achieve social mobilization.

\section{The Choice of Policy Tools for the National Sanitation City Construction in M City}

\subsection{An Overview of the Work Process of M City}

In 1989, the State Council issued the "Decision on Strengthening Patriotic Health Work", and since then, under the call of the National Aiwei Association, more than 600 cities across the country have embarked on the journey to the National Sanitation City Construction. M City, located in the eastern of Guangdong Province, was awarded the title of "Guangdong Province Sanitation City" in 2000. In 2002, the "Work Plan for the Construction of 'National Sanitation City' in M City" was formulated, which opened the mighty campaign of the National Sanitation City Construction. The entire process of construction mainly includes the following stages:

The first stage, the beginning and the exploration period (1998-2007). In order to enhance the image of the city and do more to create a humanistic brand, the Municipal Party Committee and Municipal Government of M City planned to start the "Chuang Wei" issue at the end of the last century. In 1998, it was awarded the title of "Guangdong Province Advanced Sanitation City" and in 2000, it was awarded the title of "Guangdong Province Sanitation City". After the successful construction of "Guangdong Province Sanitation City", the goal of constructing a "National Sanitation City" was established. In 2002, the "M City's 'National Sanitation City Construction' Work Plan" was established and adopted. So far, the construction of a National Sanitation City had begun to be comprehensively implemented. Through the first phase of the period from 2002 to 2006, the city's urban health infrastructure construction has been improved day by day. From 2004 to 2005, the work of constructing a "National Sanitation City" was combined with the construction of "Chinese Excellent Tourism city". The overall health level of the city has been improved qualitatively.

The second phase, the construction and development period (2007-2010). According to the "M City's 'National Sanitation City' Work Plan", from January 2007 to April 2008, it was the sprint stage of "Constructing a National Sanitation City" in M City. In order to vigorously promote the work of "Double Construction" (referring to national garden city construction and national sanitation city construction), the Municipal Party Committee and Municipal Government formulated the "Implementation Plan for the Establishment of 'National Sanita- 
tion City' activities in M City" and established the "National Sanitation City" Leading Group. In accordance with the National Sanitation City Standards of the National Aiwei Association, the tasks of each department were decomposed, and the overall objectives and main tasks were detailed and deployed.

The third phase, the adjustment period (2010). Since the establishment of the implementation plan of the "Chuang Wei" in 2007, after three years of efforts, M City has achieved certain results in the "Chuang Wei" work. At the end of 2009, it passed the provincial appraisal, and officially declared the "National Sanitation City" to the National Aiwei Association. In April 2010, the National Aiwei Office organized an unannounced interview team to conduct an investigation on the work of the city's construction of the National Sanitation City. It is believed that despite it had made certain achievements in "Chuang Wei", the problems of daily sanitation management such as urban city appearance, environmental sanitation, public places and food hygiene, etc. and the failed remediation of "six chaos" are still in place, so that based on the result from the state's unannounced visits, the declaration of "National Sanitation City" hadn't been passed, which requiring $M$ City to rectify and suspend the state acceptance.

The fourth stage is the enhancing and sprinting period (2011-2012). The failure of the third stage of the construction of a National Sanitation City had brought a great blow to the city $\mathrm{M}$. The mayor personally presided over the establishment of a national sanitation city work conference, analyzed the reasons why failed to pass the first unannounced visit by the national inspection, and deployed a comprehensive rectification task, clearly requiring that "all of the government staffs should perform their duties and do their part, and target at the problems raised by the national unannounced visits and complete the rectification task." At the same time, the municipal government executive committee conducted a special study on "Chuang Wei" once a month, and often inspected, guided and supervised the task of "Chuang Wei" through unannounced visits. In accordance with the deployment of the municipal party committee and the municipal government, all departments at all levels carefully searched for the existing problems, actively implemented the responsibility for rectification, and carried out comprehensive rectification work, focusing on the rectification of the market, environmental sanitation, key industries, and the "six chaos" phenomenon. In 2012, with the successful completion of the "National Sanitation City" gold signboard, so far, nearly 14 years of the construction of the "National Sanitation City" had temporarily ended.

\subsection{Remediation Difficulties of Sanitation Management in M City}

The history of the "Chuang Wei" in M city has been lasted for 14 years. The mobilized governance that has been used for more than ten years reflecting the difficulties in urban sanitation management. Due to the large number of projects involved in urban health (As shown in Table 1), although short-term mobilized governance is effective, it is still difficult to solve the problem fundamentally. This is also an important reason for the long-term cost of the "Chuang Wei". 
Table 1. National sanitation city unannounced visit evaluation form of city M (excerpt).

\begin{tabular}{|c|c|c|c|c|}
\hline Project & Content & value & score & Deduction note \\
\hline \multirow{3}{*}{$\begin{array}{l}\text { Smoking control } \\
20 \text { points }\end{array}$} & - Striking anti-smoking signs in public places & 8.0 & 6.4 & \multirow{3}{*}{$\begin{array}{c}\text { The smoking phenomenon in the } \\
\text { small restaurants examined } \\
\text { was obvious. }\end{array}$} \\
\hline & - Someone discourage smoking & 6.0 & 4.8 & \\
\hline & - No smoking was found & 6.0 & 4.8 & \\
\hline \multirow{3}{*}{$\begin{array}{l}\text { Public toilet } \\
20 \text { points }\end{array}$} & - Public toilets are free of charge & 4.0 & 3.2 & \multirow{3}{*}{$\begin{array}{l}\text { The public toilet infrastructure of the } \\
\text { food street inspected is poor, smelly, } \\
\text { dirty and messy. }\end{array}$} \\
\hline & - Clean and tidy, basically odorless, no flies & 7.0 & 4.9 & \\
\hline & - Clear sign & 3.0 & 2.1 & \\
\hline \multirow{3}{*}{$\begin{array}{l}\text { Garbage transfer } \\
\text { station } \\
15 \text { points }\end{array}$} & - Fully equipped & 6.0 & 4.8 & \multirow{3}{*}{$\begin{array}{l}\text { The garbage was overflow and } \\
\text { storage was not sealed in the } \\
\text { detected garbage transfer station }\end{array}$} \\
\hline & - Management is in place & 5.0 & 3.5 & \\
\hline & $\begin{array}{l}\text { - No leachate on the ground and in front of the door, } \\
\text { basically no flies }\end{array}$ & 4.0 & 2.8 & \\
\hline
\end{tabular}

1) The first is the difficulty of supervision. The National Sanitation City Awards cover a large number of projects, but the reality is that the problems of urban health and environmental issues are still serious. Due to the original segmentation between departments, it is inevitable that they will shirk responsibility to each other and "kick the ball" during the urban health management. For example, the problem of garbage dumping in the vegetable market, often involves the sanitation department and the urban management department. The lack of good joint action between these departments is an important reason for the intractability of the problem.

2) The other is the issue of a single management approach. In terms of the management and remediation of small restaurants and "five small industries" (i.e. small food business and processing units, small hairdressing and beauty shops, small bathhouse, small dance halls, etc.), at present, the health supervision and management department mainly warns the illegally operated businesses to rectify, or revokes the business licenses of which may cause serious safety hazards. However, due to the lack of daily supervision, the sanitation problems continue unabated. In order to reduce manpower and time costs, operators often disregard of rules and regulations, which makes urban health management fall into an infinite loop.

3) In addition, the lack of management resources is an important reason for restricting the social mobilization, and it is also a difficulty for urban health management. Although short-term special governance campaign can highly concentrate resources and mobilize social forces to solve the urgent governance problems, the cost of law enforcement for the special activities linked by the department is extremely high. For example, the funds, manpower, material resources and time of supervision and inspection are extremely scarce in daily governance activities, so government managers are usually not willing to launch such kind of "Special Action”.

Considering all the management difficulties above, we can easily find that under the background of constructing a national sanitation city, there are many 
assessment indicators of the urban health management, while the government departments have limited management resources and governance capabilities, which means that local governments often need to adopt a kind of temporary and one-time exercise management tools-Mobilized Governance, to achieve phased governance goals.

\subsection{Mobilized Governance in the Work of National Sanitation City Construction}

\section{1) Political mobilization in the campaign}

The size of mobilization is an important variable in the successful implementation of public policies. First of all, in terms of the political mobilization, in the initial exploration stage, the mobilization model of the municipal government was mainly reflected on the penetration of political objectives in the form of documents. Although it had not officially listed the "National Sanitation City Construction" as a key work item, it was a preliminary work strategy that gradually arouses the awareness of the "Chuang Wei" among the government staffs. Since then, the municipal government had emphasized the work plan for "Chuang Wei" in the annual government work report. The urban health and environmental construction had received great attention and the slogan of constructing "Green M City" was deeply imprinted into the grassroots management.

After the promulgation of the "Implementation Plan for the 'National Sanitation City Construction' in M City" in 2007, M City established “National Sanitation City Construction" leading group which was responsible for unifying leadership and guiding the creation of the work. All departments and units had successively established the "Chuang Wei" office, in accordance with the principle of "combination of blocks, block-based, and territorial management", which requiring health, construction, planning, municipal, public security, industry and commerce, environmental protection, transportation, and "Ai Wei" departments and other departments to work closely together to ensure the implementation of various tasks.

After the failure of the national unannounced visit in 2010, the mayor personally presided over a special meeting to comprehensively and profoundly review the reasons for the failure of the first national inspection. Subsequently, the "National Sanitation City Construction" leading group carried out personnel adjustments, and all the major supervisory units have transferred the leaders of the department level or above to the municipal government office, and directly assigned the group daily inspections in accordance with the method of delineating the film, and took the responsibility of the leaders. And the mayor and the secretary of the municipal party committee participated in the review of sanitation rectification and made internal mobilization in the form of mandatory political tasks. Under the strong political mobilization mechanism, the construction of the work had made a breakthrough and ultimately succeeded.

2) Social mobilization in the campaign

In terms of social mobilization, M City had joined various social organizations 
to carry out propaganda work through various channels. Making full use of various propaganda methods such as radio, television, newspapers and periodicals, widely publicized the significance of the National Sanitation City and the related laws and regulations, and strived to enhance the awareness of public participation. In the National Sanitation City Construction work report, since entering the sprinting period in 2007, opinions on the form of social mobilization are abundant.

In order to further improve the mobilization efficiency, M City further expanded the publicity channels. It was required to extend the mobilization force to the community, through door-to-door, peer-to-peer publicity and education through grassroots village committees, neighborhood committees and other organizations, and extensively carried out the mandatory and sweeping mobilization. In addition, the government widely used public newsstands, buses, wall billboards, outdoor public service billboards, electronic displays of hospitals and shopping malls, and mobile phone text messages, etc to propagandize the meaning of "Chuang Wei" At the same time, the government launched new media platforms such as Weibo, publicized the standards of "Chuang Wei", and opened up the government's official website and public hotlines to gather public opinion, and called on the public to report the violations of urban health management requirements so as to launch a comprehensive social supervision. $A c$ cording to statistics, in the first eight months of 2010, more than 5 million copies of publicity materials were issued, and 26,322 public service advertisements and publicity columns were set up.

\section{3) The responsibility system in the campaign}

The responsibility system is almost the most effective management method in mobilized governance. After entering the development stage of Chuang Wei in 2007, the municipal government decomposed the various indicators and tasks of Chuangwei into various departments to form an indicator system, which served as the basis for the evaluation of the next level of government. At the same time, effective rewards and punishments had been formulated to ensure the realization of the goal of "National Sanitation City Construction".

Under such high pressure, governments at all levels and related units have acted swiftly, and actively implemented rectification responsibilities, carried out comprehensive rectification work. And they adjusted the direction of rectification of the environment sanitation management in accordance with the feedback from the State Inspection Group. This series of actions made M City's achievements in the development of the "Chuang Wei" in the short period of six months, achieving a wide range of social mobilization from the inside out, and finally succeed.

\section{The Selection Logic of "Mobilized Governance" in the Process of National Sanitation City Construction in M City}

\subsection{Path Dependence of the Policy Mobilization}

The Mobilized Governance that was born in the late Republic of China is a poli- 
cy tool with a long history. As the institutional economist Douglas C. North said, as with the self-reinforcing phenomenon in the process of technological change, there are also mechanisms for increasing returns and self-reinforcing in the process of institutional change, once it embarks on a certain path, its intended direction will self-reinforce in the future development process, and affect the choices people may make in the future [2]. Considering the logic of the operation of government policies, from the political movement before the Reform and Opening-up to the preference of Mobilized Governance China in the new era, the state or the government is carried out along the traditional path of revolutionary mobilization. Looking at the history of the "Chuang Wei" in M city, it is not difficult to find that although China is a country with democratic centralism, it still relies mainly on the hierarchical structure of bureaucracy to make political decisions in actual policy decisions. At the same time, the problems of the low political sensitivity of the masses, the weak governance at the grassroots level, the imperfect social system and mechanism of the third sector such as industry associations are prominent, so that the adoption of Mobilized Governance is more efficient and maneuverable. These are the reasons why China tends to adopt the "Mobilized Governance" policy tool in the public management process.

At the same time, the National Sanitation City Standards issued by the State Council itself has a strong sense of Mobilized Governance-emphasizing speed and efficiency. That is to say, from the perspective of national mobilization, "ChuangWei" itself is promoted in the form of movement in the country. This policy decision itself has a distinctive color of traditional political movement. In the process of National Sanitation City Construction, M City followed the requirements of the relevant national documents and followed the existing experience, meanwhile naturally adopted a mobilized approach to governance.

\subsection{Realistic Constraints on Policy Resources}

With the continuous deepening of institutional reforms, Chinese rapid development of the economy and the growing material wealth in the transition do not match the immature social status and backward institutional mechanisms, which not only induces various violations of laws and regulations, but also objectively causes the government regulation to be in a weak link. Due to the diversification and complication of social public issues, there is a certain degree of "technical difficulties" in the implementation of public policies. The nature of the public problems to be solved by the state and the government in public management determines its choice of corresponding policy tools, and it also has a high dependence on governance resources in the process of governing public issues [3]. Moreover, under the objective effect of the gradual strengthening of civic awareness and the accelerated development of civil society, the continuous expansion of the total population and their increasing demand have challenged the management activities and service levels for managers. 
Judging from the construction movement of M City, the number of editors in the M City Sanitation Supervision Office was about 60 in 2009, and there were only a hundred people in the county sanitation supervision, but the "five small industries" under the scope of their supervisory duties are nearly 3000 in urban areas only. What was worse that the scope of supervision of sanitation supervision stations also includes medical and health management, occupational disease prevention and so on. On the one hand, in the face of complicated indicators of creation and protection, the people, finances and materials that the government can use are very limited. On the other hand, as an underdeveloped mountain city, the NGO breeding process is slow, and the existing social mobilization mechanism is not perfect, so that the management resources are seriously scarce. In the face of this reality, it is completely impossible to do all-day supervision of urban sanitation management. Therefore, in order to achieve policy objectives in a short time under the realistic conditions of lack of policy resources, mobilized governance is an expedient measure for government decision makers. For example, $M$ City fully mobilizes the enthusiasm of all sectors of society to participate in the construction of National Sanitation City, through money donations, material donations, and voluntary labor to solve the problem of insufficient funds.

\subsection{Structural Restrictions of the Bureaucracy}

The diversification and complication of public issues does not mean that the government must adopt mobilized governance on the governance of public issues. The choice logic of its policy tools also stems from the existing characteristics of the government bureaucracy structure. An important feature of the bureaucracy is the special division of government management and the establishment of its hierarchical system, which makes the boundaries between the internal departments of the government clear and functional. Since public issues are often not independent of other social issues and exist as a single individual, the emergence of any kind of public problem must be interdependent and influenced by other public issues [4]. In other words, it is almost impossible to design a single policy and use a single policy tool to solve a public problem in the process of public management. In the typical matrix organization structure of segmentation and criss-crossing, each department has a relatively clear division of functions of responsibility. Due to the decentralization of governance power, the government has problems of shirking responsibility and managing conflicts in governance. It is difficult for government departments to break through the existing bureaucracy system to achieve departmental linkage in daily governance. Joint operations are often inefficient due to the phenomenon of power folding and competing for limited resources with each other [4]. On the other hand, under the pressure-based system, grassroots managers are unable to face increasingly complex social contradictions in the real dilemma of managing poor resources, leading to the failure of conventional governance. Therefore, when the governance problem continues to grow through the critical point, or when the leader is actively governing with certain interests, the head of the lea- 
dership will mobilize and coordinate the joint actions of all departments and temporarily evade the power conflicts with a temporary target responsibility system, so that the mobilized governance is used as a temporary policy tool for the governance of public issues.

In terms of urban health management, due to the numerous indicators of $\mathrm{Na}$ tional Sanitation City Construction, there are 10 major projects, 66 specific indicators, and more than 500 review points. The management and supervision departments involved are also numerous, requiring health bureaus, environmental sanitation bureaus, and food and drug administrations and so on. In order to achieve effective governance within a limited time, it is necessary to break the original bureaucratic barriers, therefore, the government often hopes to adopt the Mobilized Governance to organize, mobilize, and centralize the power and resources of each functional department to achieve governance goals [5].

\section{Conclusions and Discussions}

The reason why Mobilize Governance is controversial but still become the normalized policy tool of current Chinese government governance, mainly rooted in the institutionalized soil in which it survives. In other words, the government does not hesitate to invest a lot of resources and adopt the mobilize governance has its own irresistible policy tool selection logic. Judging from the movement process of constructing a national sanitation city in M City, although it set up its goal of "Chuang Wei" in the early stage, the actual mobilization and action process were only five years, and it took more than six months to fully rush to meet the national inspection. In the case of a large gap between the previous urban sanitation situation and the National Sanitation City standard, the decision-making department had to mobilize the form of internal and external forces in a short time in order to achieve the potential purpose of quickly winning political achievements.

In summary, the reason why mobilized governance often becomes the preference of policy makers and implementers are complex. When facing the increasingly complex public issues, the resources that public managers can actually take advantage of are very limited, and in the pressure-based system, the shortage of conventional governance resources has resulted in the goal of "deliberately loading". On the one hand, conventional governance tools seem to be failed. On the other hand, the governance structure of fragmentation makes it difficult for all government agents to solve the public problem together, at this time, inherits the inertial thinking of public governance that had long consisted in the strong political mobilization in China, Mobilize Governance has become the first choice of policy makers with its ability to gather resources.

\section{Conflicts of Interest}

The authors declare no conflicts of interest regarding the publication of this paper. 


\section{References}

[1] Feng, Z.F. (2007) The Definition and Characteristics of Chinese Mobilized Governance. Journal of the Yinchuan Municipal Party College of C.P.C., No. 2, 29-32.

[2] Cao, L.H. (2014) "Path Dependence" and "Paradigm Shift" in National Governance: Rethinking Mobilized Governance. Academia Bimestris, No. 3, 81-87.

[3] Tang, X.X. (2009) The Choice of Policy Tools and the Government's Social Mobilization Ability-An Explanation of "Mobilized Governance". Study \& Exploration, No. 3, 59-65.

[4] Liu, X.B. (2012) The Dilemma and Way out of the "Againsting Pornographic and Illegal Publications" Campaign. Journal of Guangdong Institute of Public Administration, No. 4, 32-34.

[5] Ye, M. (2013) From Political Campaign to Campaigning Governance: the Mobilization Politics before and after the Reform. Journal of Huazhong University of Science and Technology (Social Science Edition), No. 2, 75-82. 